\title{
New Liquid Phases for the Gas Chromatographic Separation of Strong Bases on Capillary Columns
}

\author{
Grob, K
}

\begin{abstract}
The current practice of pretreating the solid support with free alkali to increase separation efficiency for basic compounds proved to be unsuitable for capillary columns. Instead of this, homogenous organic materials of high base strength are required. We found polyethylene imine (PEI) and polypropylene imine (PPI) to be very efficient as liquid phases of capillary columns for the separation of bases. The preparation of polymers is mentioned. Silanization or acetylation of the free hydroxyl groups of carbowax-type substrate makes them more suitable for use as liquid phases in capillary columns
\end{abstract}

DOI: https://doi.org/10.1093/chromsci/2.2.80

Posted at the Zurich Open Repository and Archive, University of Zurich

ZORA URL: https://doi.org/10.5167/uzh-155000

Journal Article

Published Version

Originally published at:

Grob, K (1964). New Liquid Phases for the Gas Chromatographic Separation of Strong Bases on Capillary Columns. Journal of Chromatographic Science, 2(2):80-82.

DOI: https://doi.org/10.1093/chromsci/2.2.80 


\section{New Liquid Phases for the Gas}

\section{Chromatographic Separation of Strong Bases on Capillary Columns}

by K. Grob, F. J. Burrus \& Cie, Boncourt and Department of Organic Chemistry, University of Zurich, Switzerland

\section{Abstract}

The current practice of pretreating the solid support with free alkali to increase separation efficiency for basic compounds proved to be unsuitable for capillary columns. Instead of this, homogenous organic materials of high base strength are required. We found polyethylene imine (PEI) and polypropylene imine (PPI) to be very efficient as liquid phases of capillary columns for the separation of bases. The preparation of polymers is mentioned. Silanization or acetylation of the free hydroxyl groups of carbowax-type substrate makes them more suitable for use as liquid phases in capillary columns.

The separation of basic amines by GLC has long been a serious problem, but is now solved by alkalitreatment of the solid support prior to coating with the liquid phase. Increasing number of authors (1-3) consider this procedure the best way for obtaining sharp and symmetric peaks; the most comprehensive discussion of the subject was recently published by Ottenstein (4).

One of the drawbacks of the alkali treatment is, however, the fact that most of the conventional liquid phases are altered when free alkali ( $1-6 \%$ by weight of the support) is added $(2,3)$, particularly at temperatures over $150^{\circ} \mathrm{C}$. In some instances, isomerization and breakdown reactions of the injected substances are also initiated by the alkali present (5).

In our attempts to analyze fresh cigarette smoke by GLC (6) we vere facing the difficulty that the smoke contains acidic and neutral substances as well as numerous aliphatic and aromatic amines. This very large number of smoke constituents necessitates the use of columns with the highest possible separation efficiency, i.e. capillary columns. As far as we know the

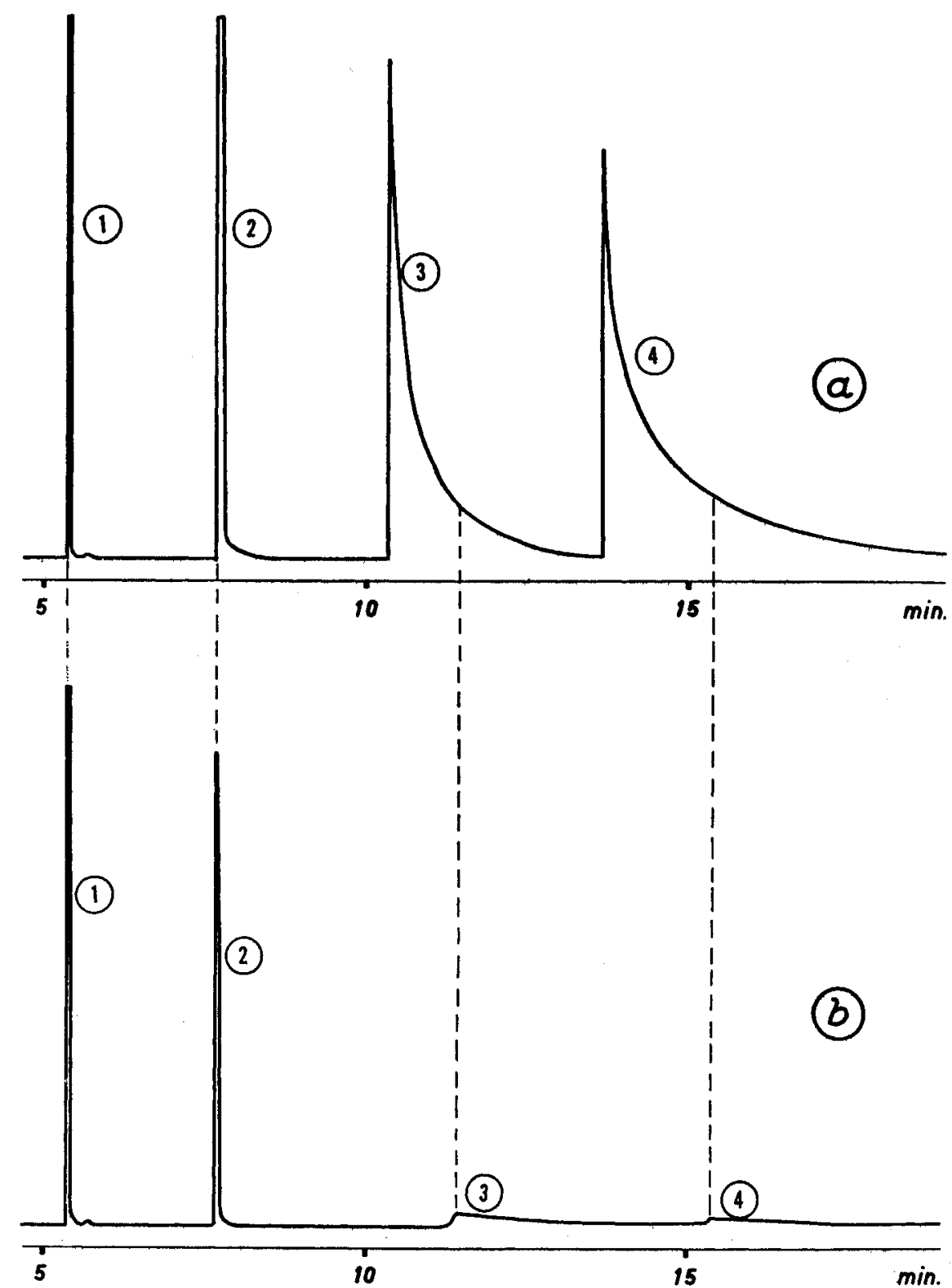

Figure 1/a-b. Column: 50 meters $\times 0.25 \mathrm{~mm}$ i.d., coated with silanized Carbowax 2000 . Column temperature: $120^{\circ} \mathrm{C}$, isothermal operation. Carrier gas $\left(\mathrm{N}_{2}\right)$ inlet pressure 1.5 atm (gauge). Sample volume: $0.5 \mu$ g ether solution. Split ratio: $1 / 50$. Sample components: 1 diethyl ether, 2 toluene, 3 pyridine, 43 -methylpyridine. Concentration of each component in the solution: (a) $10 \%$, (b) $1 \%$. 
separation of basic amines with capillary columns has not yet been reported.

With conventional liquid phases such as Apiezon grease, silicon oils, polyesters, polypropylene glycol and polyphenyl ether on 0.25 and 0.5 mm i.d. stainless steel capillaries, we were unable to obtain any reasonable separation of amine mixtures. Even the addition of nonionogenic detergents (tail reducers) was ineffective.

Somewhat better but still unsatisfactory results were achieved on columns coated with Carbowax 1000. In order to assure a uniform coating of the steel capillary, we had to reduce the surface tension of the Carbowax by silanizing or esterifying its hydroxy-groups. The results are illustrated in figure 1. Reasonable peaks, but with severe tailing for the amines, were obtained when analyzing an ether solution containing toluene, pyridine and 3-methylpyridine, each in $10 \%$ concentration. Decreasing the concentration to $1 \%$ resulted in a much poorer resolution for the amines: due to excessive tailing their peaks tend to disappear and their retention times are also increased while peaks of non-polar substances (e.g. toluene) keep their geometry and retention time. Neither the addition of alkali to the liquid phase nor column pretreatment with alkali improved separation efficiencv.
We conclude from these results that the function of the alkali in the column is not the inactivation of the acidic or other active sites of the solid support, but also, to make the liquid phase as a whole more alkaline than the sample components.

We therefore searched for a homogenous liquid phase which, in itself, would be a strong base. Organic compounds with phenyl or benzyl amine groups provide good thermostability and low vapor pressure yet proved to be not sufficiently basic for our purpose. On the other hand, most of the stronger bases are deficient in thermostability. Finally two polymer amines were selected, both having sufficient base strength combined with reasonable thermostability:

\section{Polyethylene imine (PEI) :} $\left(-\mathrm{CH}_{2}-\mathrm{CH}_{2}-\mathrm{NH}-\right)_{n}$

Polypropylene imine (PPI) : $\left(-\mathrm{CH}_{2}-\mathrm{CH}-\mathrm{NH}-\right)_{n}$ $\mathrm{CH}_{3}$

Whereas PPI is not available commercially in Europe, PEI with a molecular weight of about 40,000 is manufactured by BASF, but its viscosity is far too high for use as a liquid phase. Both PPI and PEI can be polymerized from the respective monomers to a molecular weight of about 1000 . Our most serious difficulty consisted in finding a volatile liquid of moderate polarity that would dissolve the water soluble polymers; finally diethyl amine was found to be well suited for this purpose.

\section{Experimental}

\section{Instrument}

Chromatograph model $\mathrm{C}$ of Carlo Erba, Milano, with flame ionization detector and linear temperature programming of the column.

\section{Liquid Phases}

\section{a) PEI}

A polymer of $\mathrm{MW}=800$ was prepared according to the literature $(7,8)$, with formic acid as a polymerization initiator. Complete drying out of the aqueous solution is facilitated by adding an equal weight of silanized Carbowax 1000 , which improves at the same time the viscosity characteristics of the material.

\section{b) PPI}

This polymer was prepared in the same manner, but with $\mathrm{HCl}$ as initiator. Since PPI is less polar than PEI, drying is easier and can be accomplished without any additive.

Both polymers violently absorb water and carbon dioxide. They are, therefore, stored in diethyl amine

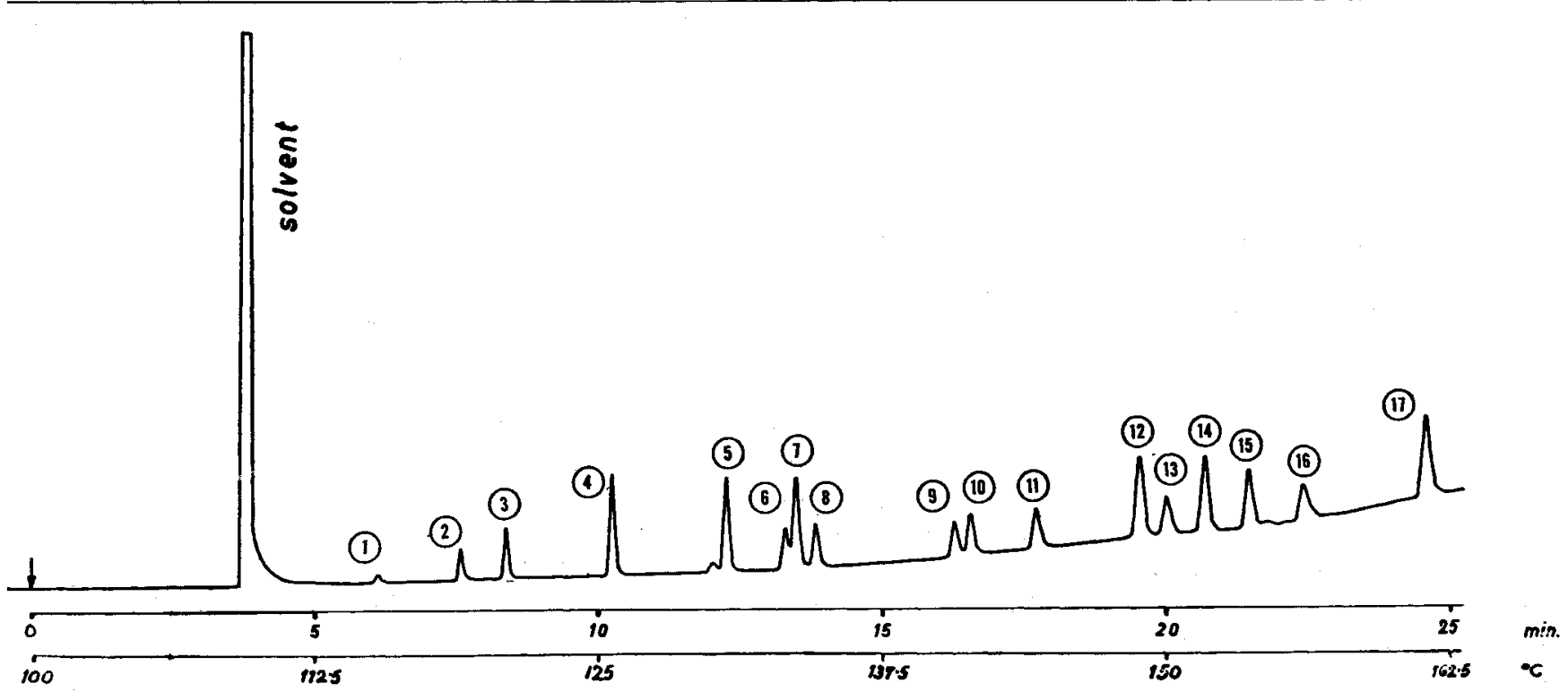

Figure 2. Column: 50 meters $\times 0.25 \mathrm{~mm}$ i.d., coated with PPI. Column temperature: programmed from $100^{\circ} \mathrm{C}$ at a rate of $2.5^{\circ}$ $\mathrm{C} / \mathrm{min}$. Carrier gas $\left(\mathrm{N}_{2}\right)$ inlet pressure: $1.5 \mathrm{~atm}$ (gauge). Sample components: 1 pyrrolidine, 2 piperidine, 3 pyridine, $42-$ methylpyridine, 5 2,6-dimethylpyridine, 6 3-methylpyridine, 7 4-methylpyridine, 8 2-ethylpyridine, 9 2,5-dimethylpyridine, 10 2,4-dimethylpyridine, 11 2,3-dimethylpyridine, 12 2,4,6-trimethylpyridine, 14 4-ethylpyridine, 14 2,3,6-trimethylpyridine, 15 3,5-dimethylpyridine, 16 pyrrole, 17 3,4-dimethylpyridine. Concentration of each substance in the solution about $0.1 \%$. 


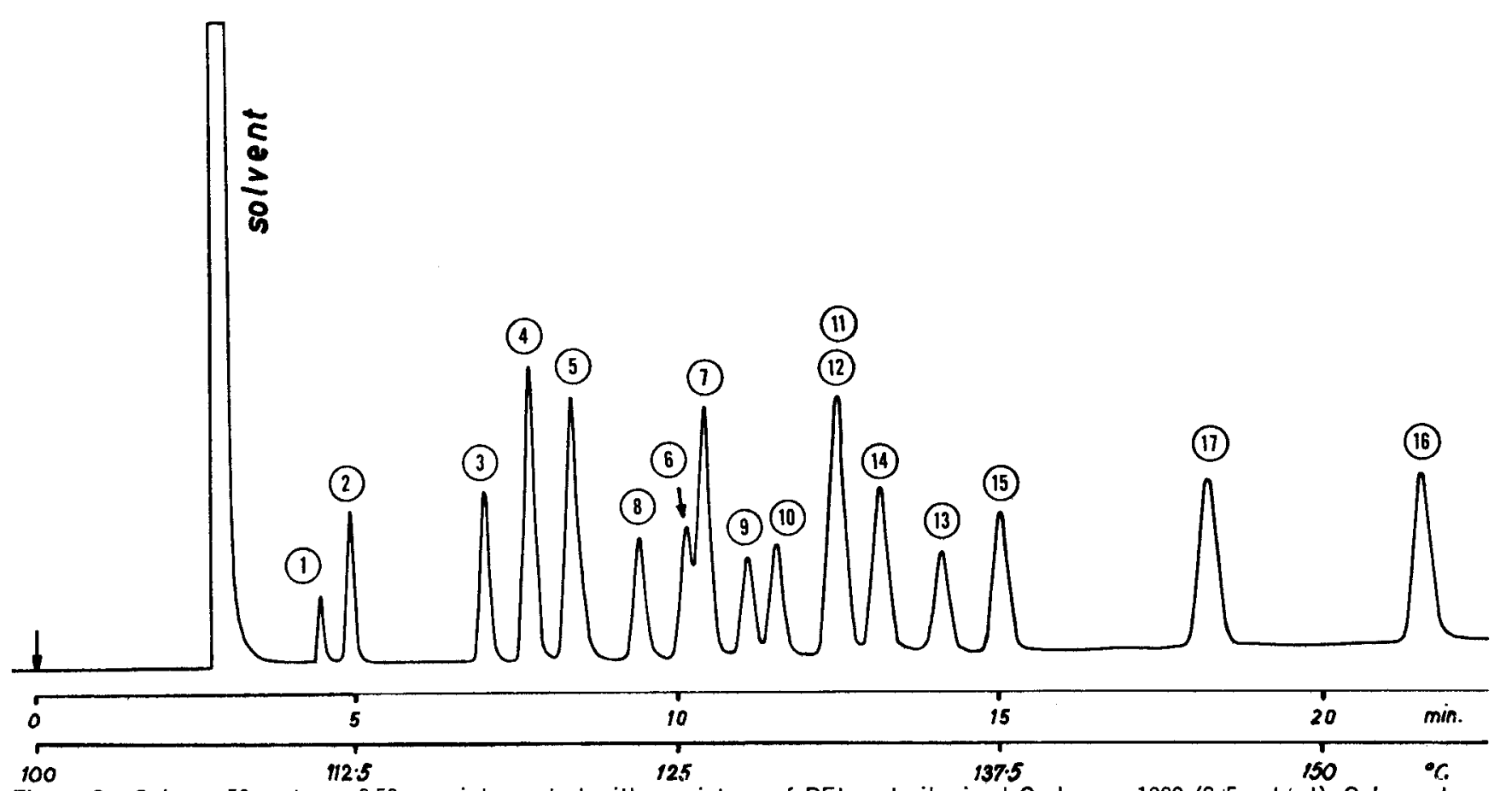

Figure 3. Column 50 meters $\times 0.50 \mathrm{~mm}$ i.d., coated with a mixture of $\mathrm{PEl}$ and silanized Carbowax 1000 (2/5, wt/wt). Column temperature: programmed from $100^{\circ} \mathrm{C}$ at a rate of $2.5^{\circ} \mathrm{C} / \mathrm{min}$. Carrier gas $\left(\mathrm{N}_{2}\right)$ inlet pressure: $0.3 \mathrm{~atm}$ (gauge). Sample volume: 1.0 $\mu \mathrm{l}$ of the test solution. Split ratio: 1/20. Sample components and concentration as in Figure 2.

solution over fresh calcium oxide. After evaporation of the solvent, samples of both polymers were sealed in glass tubes under nitrogen and kept for several days at $230^{\circ} \mathrm{C}$. Thereby the liquids remained absolutely clear and colorless. They turned dark brown, however, when acetone had been used as a solvent instead of diethyl amine.

\section{c) Silanized Carbowax}

$50 \mathrm{~g}$ of Carbowax 1000 and 8.0 $\mathrm{g}$ of hexamethyldisilazane are kept at $80^{\circ} \mathrm{C}$ for 5 hours with a slow stream of nitrogen bubbling through the mixture. If contact with air is avoided, the liquid remains completely colorless. Cleaning of the product is not necessary since an excess of silazane or some of its byproducts are easily evaporated from the column.

\section{Columns}

Stainless steel capillaries $50 \mathrm{~m}$ long with 0.25 or $0.5 \mathrm{~mm}$ i.d., respectively, were coated with $12 \%$ solutions of the polymers. The temperature of the capillary, the nitrogen pressure and the quantity of the solution forced through the column were chosen so that the liquid passed the capillary in 1-2 hours.
The columns were conditioned under normal nitrogen pressure at $160^{\circ}$ $\mathrm{C}$ for 12 hours.

\section{Results and Discussion}

The described procedure enabled us to obtain sharp and symmetric peaks of basic amines, with almost complete resolution of the pyridine derivatives (figures 2 and 3 ). The retention times remained constant even when the concentrations were significantly varied. The single constituents of cigarette smoke being present only in minute amounts, test solutions of low concentration had to be used. The solution used for the runs illustrated in Figures 2 and 3 contained, e.g. pyridine, in a ratio of 1:1000 with respect to the ether solvent. Our polyimine columns are thus considerably less sensitive to excess solvent than ordinary capillary columns. At normal working temperatures, polyimine coatings are rapidly altered upon contact with air or other oxydizing agents; therefore, nitrogen of at least $99.999 \%$ purity is required as carrier gas.

Within the range of $100-150^{\circ} \mathrm{C}$, we have used the columns continuously for several weeks without observing any alteration. After about 20 runs with temperature programming up to $190^{\circ} \mathrm{C}$ severe broaden- ing of the peaks occurred. In our opinion, reaction of the polyimines with the stainless steel rather than the higher temperatures is responsible for this finding.

Below $100^{\circ} \mathrm{C}$ retention times increase greatly and correspondingly broadening of the peaks takes place, apparently due to excessive viscosity of the liquid phase. Work is in progress to overcome this limitation. We hope to expand the practical temperature range in both directions by mixing the polyimines with other coating materials.

\section{Literature Cited}

1. Link, W. E., Morrissette, R. A., Cooper, A. D., and Smullin, C. F., J. Am. Oil Chem. Soc. 37: 364 (1960).

2. Smith, E. D., and Radford, R. D., Anal. Chem. 33: 1160 (1961).

3. Cincotta, J. J., and Feinland, R., Anal. Chem. 34: 774 (1962).

4. Ottenstein, D. M., J. Gas Chromatog. 1, No. 4:11 (1963).

5. Kenney, R. L., and Fisher, G. S., J. Gas Chromatog. 1, No. 8: 19 (1963).

6. Grob, K., Beitrage zur Tabakforschung 1962, No. 9:315.

7. Leibnitz, E., Konnecke, H. G., and Gawalek, G., J. Prakt. Chem. 278: 289 (1958).

8. Kern, W., and Brenneisen, E., J. Prakt. Chem. 159: 193 (1941).

Manuscript received October 19, 1963. 